- Lúcio Antônio Garcia Dias

- Juvenal da Rocha Torres Neto

- Marcel Vinícius Aguiar

de Menezes

- Jorge Gontran Torres de Menezes

\section{Anestesia local em cirurgias orificiais}

Hospital Universitário e Hospital São Lucas, Aracaju, Sergipe
INTRQDUCุÃa

Estudo prospectivo que visa avaliar a eficácia perioperatória da técnica de anestesia local no tratamento cirúrgico de afecções proctológicas, comparando grupo de estudo (anestesia local) ao grupo controle (bloqueios espinhais).

MÉTIDIS

Foram estudados, no período de março de 2003 a agosto de 2004, 92 pacientes com idade entre 17 e 78 anos, encaminhados para tratamento cirúrgico devido a doenças anorretais. Os pacientes foram divididos aleatoriamente em três grupos, sendo o grupo A formado por 51 pacientes $(55,6 \%)$ submetidos à anestesia local; grupo $\mathrm{H}$, com 24 pacientes $(26 \%)$ submetidos à raquianestesia; $\mathrm{e}$ o grupo C, com 17 pacientes (18,4\%) submetidos a bloqueio peridural. Todos eles foram submetidos à sedação padrão e a bloqueios preconizados, e operados pela mesma equipe cirúrgica.

RESULTADOS

O padrão da anestesia foi ótimo em 88 pacientes $(94,6 \%)$ e bom em 2 pacientes (5,4\%), nos quais houve a necessidade de administração de anestésico adicional para bloqueio locorregional. A dor pós-operatória foi avaliada em uma escala graduada de 0 a 10 . Obtivemos para o grupo A uma média de 6,16; para o grupo $\mathrm{H}$ de 4,92, e para o grupo C de 5,64. Negaram dor anorretal após a cirurgia 35 pacientes, sendo 17 casos (48,5\%) do grupo A, 13 casos (37\%) do grupo He 5 (14,5\%) do grupo C. O início da dor pós-operatória após o procedimento cirúrgico ocorreu em média, no grupo A, em 8 h, no grupo $\mathrm{H}$ em 9 h e 30 min, e no C, em 8 h e 9 min. Quanto ao tempo de internação hospitalar, o grupo A teve uma média de $14 \mathrm{~h}$ e $30 \mathrm{~min}$, o grupo $\mathrm{H}$ de 21 h e $52 \mathrm{~min}$, e o C de 23 h e $54 \mathrm{~min}$.
DISCUSSÃロ

Nesta casuística pudemos observar que a técnica de anestesia local apresentou menor custo, maior aceitabilidade por parte do paciente e menor incidência de complicações, exceto em relação à sensação de peso anorretal. $\mathrm{O}$ início da dor foi mais precoce se comparado aos bloqueios espinhais, porém com freqüência e intensidades semelhantes.

CロNCLUSÃa

A técnica de anestesia local é exeqüível e seu uso traz benefícios à cirurgia orificial.

REFERÊNCIAS

1. Sobrado CW, et al. Cirurgia ambulatorial sob anestesia local em proctologia: experiência e análise do resultado de 503 operaçôes. Rev Bras Coloproct. 2001;21(4):228-33.

2. Quilici EA. Doenças anorretais. 1르. ed. Sāo Paulo: Lemos; 2002.p.5-23.

3. Tagliolato Jr. Analgesia de conduçăo na cirurgia anorretal. Aspectos técnicos. Rev Bras Coloproct. 1993;13(3):113-6

4. Wetcher HV. Anestesia Ambulatorial. In: Tratado de Anestesiologia Clínica. 1a edição. São Paulo: Manole; 1993.p.1619-66.

5. Smith IE. Ambulatory surgery for anorectal diseases: an update. South Med J. 1986;79:163-6.

6. Sobrado CW, Habr-Gama A. Hook-needle puncture: a new techinique of local anesthesia for anorectal surgery. Dis Colon Rectum. 1996:39:1330-1.

Endereço para correspondência:

Lúcio Antônio Garcia Dias

Rua Cristóvão de Barros, 1 - apto. 301 - Bairro 13 de Julho

Aracaju (SE) - CEP 49020-180

Tel. (+55 79) 3246-5700 / 8808-0658

E-mail: luciogarcia@qoq.com.br 